\title{
Docetaxel-related interstitial pneumonitis
}

This article was published in the following Dove Press journal:

Therapeutics and Clinical Risk Management

9 December 2015

Number of times this article has been viewed

\author{
Chung-Jen Wang \\ Hou-Tai Chang \\ Cheng-Yu Chang \\ Division of Chest Medicine, \\ Department of Internal Medicine, \\ Far Eastern Memorial Hospital, New \\ Taipei City, Taiwan
}

\begin{abstract}
Docetaxel (Taxotere ${ }^{\circledR}$ ) is an agent that is indicated for the treatment of patients with locally advanced or metastatic non-small-cell lung cancer. In recent years, docetaxel-related interstitial lung disease (ILD) has been reported in several case series studies. The onset of ILD occurred $\sim 10-20$ days (median time: 18 days) after docetaxel administration. Here, we reported the case of a patient who had pulmonary toxicity of ILD within 3 days after using a relatively low-dose docetaxel administration. Although some articles have described patients who progressed to respiratory failure and needed intubation, this patient responded well to steroid treatment and discontinued docetaxel administration.
\end{abstract}

Keywords: docetaxel, interstitial lung disease

\section{Case report}

A 47-year-old male smoker presented with chronic cough and dyspnea for 2 months. The chest X-ray (Figure 1A) and chest computed tomography (CT) showed right lower lung tumor and lobulated effusion (Figure 1B), and the lung window showed no interstitial lesion (Figure 1C). Pathological immunostaining was positive for p63 and CK 7 and negative for CK20 and TTF-1, which indicated squamous cell carcinoma. After a series of studies, including brain CT and whole body bone scan, the cancer was classified as cT4 $(9.87 \mathrm{~cm}) \mathrm{N} 3 \mathrm{M} 0$, stage IIIb, due to multiple enlarged lymph nodes in the retrocaval, prevascular, bilateral lower paratracheal, subcarinal, and right interlobar regions. He received chemotherapy with docetaxel $\left(30 \mathrm{mg} / \mathrm{m}^{2}\right.$, day 1) after premedication with intravenous dexamethasone (10 mg). He developed severe cough and progressive dyspnea 3 days after administration. He had no systemic inflammatory or infection symptoms at the time. In room air, the arterial blood gas analysis revealed: pH, 7.362; partial pressure of carbon dioxide, $40.3 \mathrm{mmHg}$; partial pressure of oxygen, $44.6 \mathrm{mmHg}$; and bicarbonate $\left(\mathrm{HCO}_{3}\right)$ level, $23.4 \mathrm{mmol} / \mathrm{L}$. The serum examination showed no leukocytosis or neutropenia. The chest X-ray revealed diffused interstitial infiltrates (Figure 2A), and chest CT showed diffuse ground glass opacities at bilateral lung fields and nonsegmental predominance of lung opacity without prominent hilum engorgement (Figure 2B). The patient had no heart disease history and fair urine output. The cardiac echography showed good left ventricular ejection fraction (74\%). The fluid overload or cardiogenic edema was less likely.

Under the impression of interstitial lung disease (ILD), steroid (intravenous methylprednisolone, $2 \mathrm{mg} / \mathrm{kg}$ ) and broad spectrum antibiotics were prescribed. We tapered the steroid gradually within 14 days of treatment. The clinical symptoms, chest X-ray (Figure 3A), and chest CT (Figure 3B) showed significant improvement after treatment. He also received serological tests, sputum culture, blood culture, Legionella pneumophila, Mycoplasma pneumoniae, Chlamydophila pneumonia, influenza virus 


\section{A}

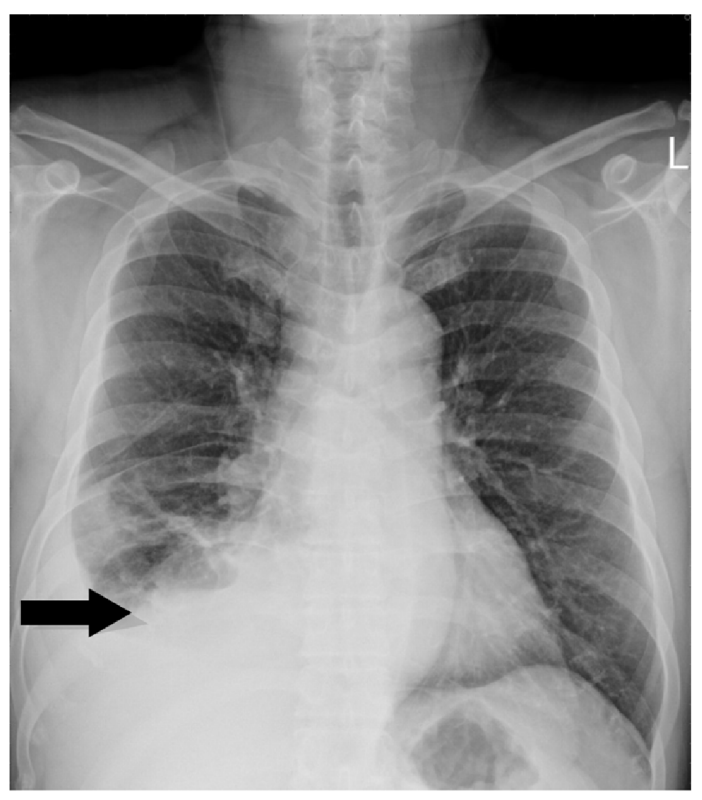

B

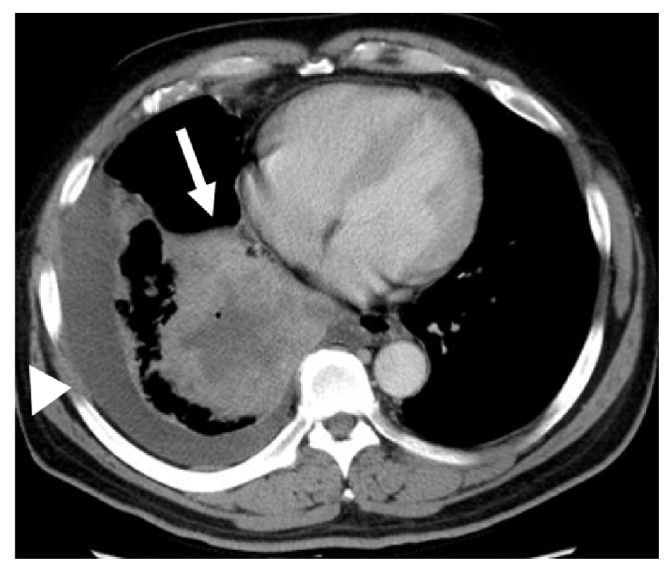

C

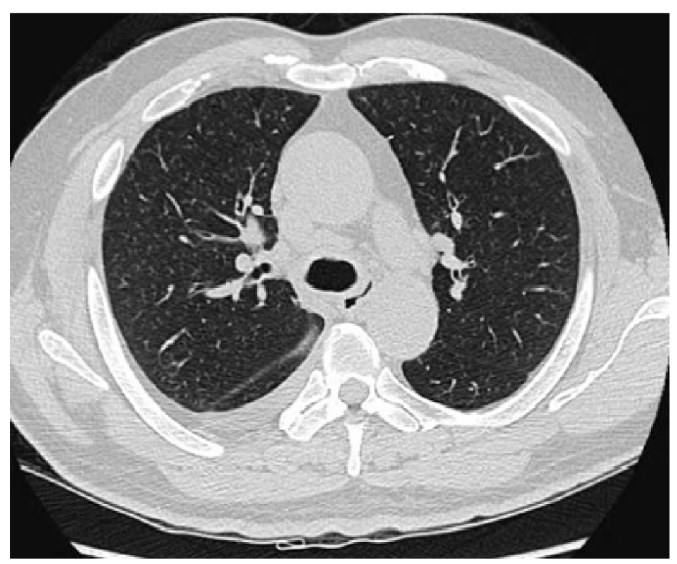

Figure I Before chemotherapy.

Notes: (A) A chest X-ray shows right lower lung consolidation and pleural effusion (black arrow). (B) A chest CT shows a soft tissue mass measured as $98.7 \times 87.4 \times 82.7 \mathrm{~mm}^{3}$ in the right lower lung field (white arrow) with central necrosis and lobulated pleural effusion (white arrow head). (C) A chest CT shows no interstitial lung disease or lymphangitis carcinomatosis.

Abbreviation: $\mathrm{CT}$, computed tomography.
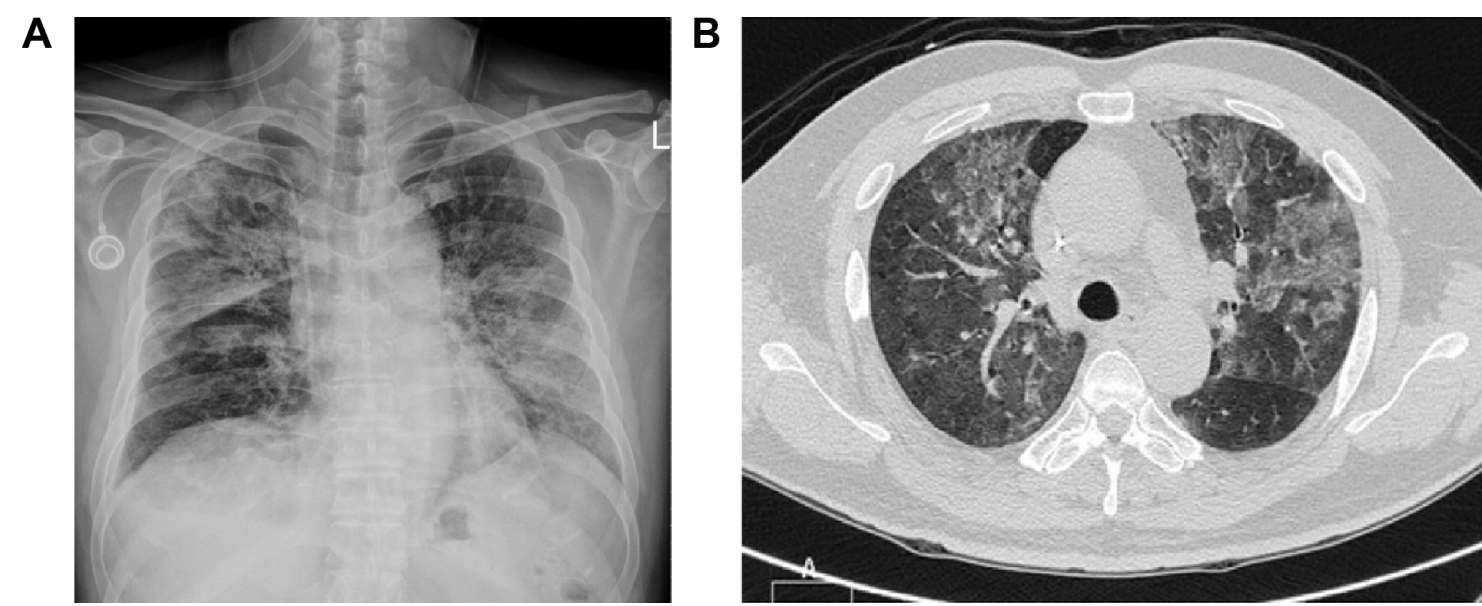

Figure 23 days later following chemotherapy.

Notes: (A) A chest X-ray shows increased interstitial lung markings bilaterally; the implanted port was placed at the right subclavian vein. (B) A chest CT shows diffuse ground glass opacity at the bilateral lung fields.

Abbreviation: $\mathrm{CT}$, computed tomography. 
A

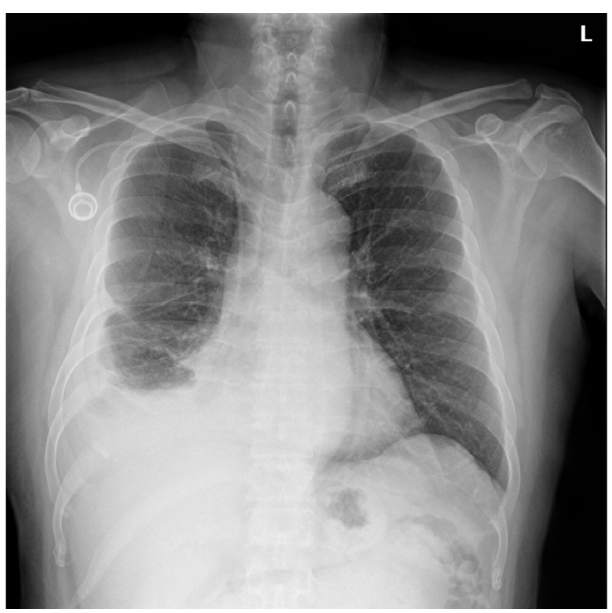

B

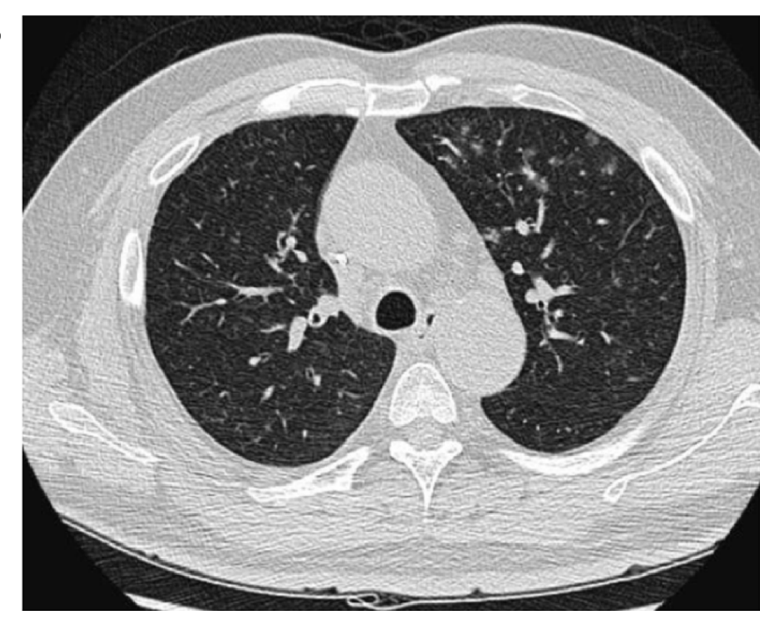

Figure 3 After steroid administration.

Notes: (A) A chest X-ray shows no obviously increased lung marking, and the implanted port was placed at the right subclavian vein. (B) The repeated chest CT shows marked improvement in ground glass opacity.

Abbreviations: CT, computed tomography; L, left side.

A and B, and autoimmune profile examinations, and all tests showed negative findings. Written informed consent was obtained by the patient. Permission of case report publication from the Ethics Review Committee of the Far Eastern Memorial Hospital was also sought.

\section{Discussion}

Among previously published cases of docetaxel-related interstitial pneumonitis, this is the first to describe a patient who developed acute pulmonary toxicity within 3 days after administration of low-dose docetaxel $\left(30 \mathrm{mg} / \mathrm{m}^{2}\right)$. Taxanes are known to cause proliferation of cytotoxic T-cells, leading to a hypersensitivity type of lung damage, or might cause direct pulmonary damage through reactive oxygen metabolites. According to our report, low-dose docetaxel treatment was less toxic but not an effective prevention method of lung damage. The physicians should be aware of the possibility of interstitial pneumonitis by the patient's symptoms and daily physical examination after administration of taxanes.

The acute pulmonary toxicity of ILD after docetaxel administration is an uncommon adverse event in patients with cancer. ${ }^{1}$ Approximately $4.6 \%$ of patients experience pulmonary toxicity induced by triweekly conventionaldose docetaxel monotherapy $\left.\left(75 \mathrm{mg} / \mathrm{m}^{2}\right)\right)^{2,3}$ Pneumonitis in most cases occurred after two cycles with a conventional dose. ${ }^{3}$ The incidence of pulmonary toxicity is more related to the docetaxel delivery schedule than the dose, that is, a weekly schedule leads to lower myelosuppression but more pneumonitis than triweekly administration. ${ }^{4}$ Moreover, the largest published series of docetaxel-related interstitial pneumonitis reported 18 different cases of a total of 392 patients with metastatic non-small-cell lung cancer treated with docetaxel. The time from the last docetaxel administration to the onset of toxicity findings on the chest radiograph was approximately 10-20 days (median time: 18 days $)^{5}$

Although docetaxel-related side effects are rare, the mortality rate is high. The overall mortality rate due to drug-associated interstitial fibrosis, estimated based on published case reports, appears to be $\sim 40 \%$, with 12 deaths among 30 cases in which mortality data were available. ${ }^{2}$ This result was also seen in another literature review, which summarizes a total of 31 cases of taxane-induced pneumonitis, in which $35 \%$ needed ventilator support, and the mortality rate was $42 \%$ in the whole group; those in need of intubation had a mortality rate of $82 \% .^{6}$

The treatment of choice is administration of systemic glucocorticoid therapy in selected patients in whom an infectious etiology was excluded with appropriate cultures. The patient is usually treated with prednisolone $40-60 \mathrm{mg} /$ day for 2-3 weeks; 60-240 mg/day may be used in patients who have impending respiratory failure, along with a slow and careful tapering-off period. ${ }^{7}$

Although the occurrence of docetaxel-related ILD is rare, it will lead to respiratory failure if treatment is delayed. ILD responds well to steroid treatment and discontinuation of docetaxel administration. Our case indicates the acute pulmonary toxicity of ILD when administering docetaxel.

\section{Disclosure}

The authors report no conflicts of interest in this work. 


\section{References}

1. Eivind S, Gunhild H, Karsten G, et al. Lethal pneumonitis after docetaxel chemotherapy: case report and review of the literature. Acta Oncol. 2013; 52:1034-1038.

2. Read WL, Mortimer JE, Picus J. Severe interstitial pneumonitis associated with docetaxel administration. Cancer. 2002;94:847-853.

3. Wang GS, Yang KY, Perng RP. Life-threatening hypersensitivity pneumonitis induced by docetacel (taxotere). Br J Cancer. 2001;85: 1247-1250.

4. Chen YM, Shih JF, Perng RP, Tsai CM, Whang-Peng J. A randomized trial of different docetaxel schedules in non-small cell lung cancer patients who failed previous platinum-based chemotherapy. Chest. 2006;129: 1031-1038.
5. Tamiya A, Naito T, Miura S, et al. Interstitial lung disease associated with docetaxel in patients with advanced non-small cell lung cancer. Anticancer Res. 2012;32:1103-1106.

6. Nagata S, Ueda N, Yoshida Y, Matsuda H, Maehara Y. Severe interstitial pneumonitis associated with the administration of taxanes. $J$ Infect Chemother. 2010;16:340-344.

7. Khan A, McNally D, Tutschka PJ, Bilgrami S. Paclitaxel-induced acute bilateral pneumonitis. Ann Pharmacother. 1997;31:1471.

\section{Publish your work in this journal}

Therapeutics and Clinical Risk Management is an international, peerreviewed journal of clinical therapeutics and risk management, focusing on concise rapid reporting of clinical studies in all therapeutic areas, outcomes, safety, and programs for the effective, safe, and sustained use of medicines. This journal is indexed on PubMed Central, CAS,
EMBase, Scopus and the Elsevier Bibliographic databases. The manuscript management system is completely online and includes a very quick and fair peer-review system, which is all easy to use. Visit http://www.dovepress.com/testimonials.php to read real quotes from published authors.

Submit your manuscript here: http://www.dovepress.com/therapeutics-and-clinical-risk-management-journal 